\title{
Form-finding Tensegrity Models Approach with Reverse Engineering
}

\author{
Hashem Hashemnejad ${ }^{1}$, Asem Sharbaf ${ }^{2} \&$ Mitra Sharbaf $^{3}$ \\ ${ }^{1}$ Associate Professor at Department of Architecture, Architecture and urban Faculty, Iran University of Science \\ and Technology, Tehran, Iran \\ ${ }^{2}$ Master of Scienceat Department of Architecture, Architecture and urban Faculty, Iran University of Science and \\ Technology, Tehran, Iran \\ ${ }^{3}$ Master of Science at Department of Architecture, Architecture Faculty, Tabriz Branch, Azad Islamic University, \\ Tehran, Iran \\ Correspondence: Asem Sharbaf, Master of Scienceat Department of Architecture, Architecture and urban Faculty, \\ Iran University of Science and Technology, Tehran, Iran. E-mail: asem_sharbaf@yahoo.com
}

Received: April 27, 2016

doi:10.5539/mas.v10n9p112
Accepted: May 22, 2016

Online Published: June 7, 2016

URL: http://dx.doi.org/10.5539/mas.v10n9p112

\begin{abstract}
Background/Objectives:

After recent achievements in the field of Tensegrity structure, many Tensegrity models have been investigated and evaluated. Tensegrity models have been used as symbolic or covering vast area such as fuller's dome and other stuffs. These usages do not have sufficient attention to synthesis of architectural and structural space together.
\end{abstract}

Methods/Statistical analysis:

The method of this article, based on simulation and modeling of a sample structure by analyzing flow of internal forces, is adaptive methode. Restriction of exited structures to a hammock and then analysis its force flow, and consequently classify it to tensile and compressive members is the base of manner. By gathering information about Tensegrity structures and their behavior according to several definition of structural engineers and also architects, we commence combination of facts based on adaptation of existed structures with Tensegrity rules. Then, by finding a Tensegrity model and creating a replica of hammock Tensegrity, it shows the ability of structure specially in term of statistic. This outcomes can help us to develop new system of form - finding models.

\section{Findings:}

This system can make us able to develop modeling of Tensegrity. In the recent years, form - finding method almost base on symmetric models to expand as cover structure for vast spans. By this manner, we can design asymmetric models consist of synthesis of structural and architectural space.

Application/Improvements:

Form - Finding method can be developed in order to increase quality of building in term of weight of structure, flexibility, decreasing proportion of used material to its resistance and so on. In addition, we can produce asymmetric models which contain architectural space into Tensegrity structure.

Keywords: tensegrity structure, adaptation method, hammock, simulation and modeling

\section{Introduction}

In recent years, many researches have been done on the relationship of structure and architecture. So many definitions are provided such as "form follow function", "form follow force", etc... But the important among them is combination of architecture and structure as a whole one that each one is a complementary and an integral part of the effect achieved by the building group. However, factors that make distinguishment between architectural and structural definition is related to predominant attitudes and ideologies throughout history (Macdonald, 2001).

What seems important today, increasing advances in the field of structural engineering has been the cause of imbalance between Architecture and structure. Advanced Structures are designed to have high efficiency in the 
structure between used Materials and applied force. Prefabricated, easy installation and cost of construction and recycled materials, including the factors that have been involved by the building engineering groups. Space frame structures can supply the demands of Structural Engineers. Space frame structures discovered by Graham Bell, until today there have been great advancement and somehow use it in buildings with large span and varied forms are possible. Tensegrity Structures is a new generation of space frame structures, which can be the ideals of structural engineers in order to design structures with tensile and compressive members exclusively to achieve.

Three men have been considered the inventors of Tensegrity: Richard Buckminster Fuller, David Georges Emmerich and Kenneth D. Snelson (Macdonald, 2001). Although all of the three have claimed to be the first inventor, R. Motro $(1987,2003)$ mentions that Emmerich (1988) reported that the first proto-Tensegrity system was created by a certain Karl Ioganson in 1920 (Gómez, 2004).

Several explanations have been offered by researchers in the Tensegrity structures field. But, in a general purpose, Tensegrity structures can be defined such as:

Anthony Pugh gives the following definition of Tensegrity:

A Tensegrity system is established when a set of discontinuous compressive components interacts with a set of continuous tensile components to define a stable volume in space (Pugh, 1976).

But Fuller knew that Tensegrity definition is universal:

"All structures, properly understood, from the solar system to theatom, are Tensegrity structures. Universe is Omni tensional integrity.” R. B. Fuller (Gómez, 2004).

Fuller acknowledged that all existing structures have associated with compressive and tensile members. With a bit attention to the forces acting on the structure, can be concluded that the secondary forces such as bending, shear and torsion are resulted of both tensile and compressive forces. According to Fuller's researches in the field of Tensegrity structures, it can be inferred that the existing structures in the universe obey the law of Tensegritystructures. Structure that discontinuous compressive members floated in the network of tensile members which all members are organized according to axial forces. Due to the high efficiency of consumption materials, use of materials and high technology, despite the high cost of modified material such as carbon fiber, Nano technology in construction, will be possible. Despite all the advantages, the complex Tensegrity structures have created a design limitation.Unfortunately, what has been achieved until today, beautiful sculptures, retaining structures and covering structures for large space have been used.

In recent years, Tensegrity structures in various fields such as construction, space stations, satellite dishes, studied at Deployable Tensegrity Structures for Space Applications by Gunnar Tibert (2002), masts (Tibert \& Pellegrino, 2003), temporary structures, pedestrian bridge, sector of sphere and others have been studied.

But, lack of architectural space into Tensegritystructures is notable. The method has been used for this purpose is the reverse procedure. In other words, the use of existing structures and applies the defined princile of Tensegrity on it. Therefore, it is better to focus on simple structure of Hammock. Hammock has been chosen because of different reason. First of all this paper are adjusted according to master thesis which was international exhibition of construction industry in kish island approach with Tensegrity structure.

The other one is Structure, which is used in the hammock, is very basic but is advanced. Hammock structure includes tensile string, compressive stud and membrane structure. By studying the structure of a hammock and a comprehensive Tensegrity law, it can be devised model that has architectural space into Tensegrity structures. So that asa hammock structure, User has been surrounded in the network structure and each member based on their behavior structure is in their special place. For this purpose, a replica of the model is made to verify the structural behavior of the model should be evaluated. This replica includes compressive rod, tension members that have been retained in cable network structures.

Finally, it can be inferred that Tensegrity structures are the base of design. So that they are supposed the prominent elements at the architectural design. According to mentioned steps, efforts are based on appropriate solutions in order to expand design area of Tensegrity models by using reverse engineering.

\section{Interaction Between Structure and Architecture}

From the inception of human life in different periods of history, humans have always faced Diverse challenges and uneven. Various factors have been implicated in the formation of architecture so focused on the money, different architecture is formed. Human evolution process has created many diverse casts which architects have been faced. It has attracted the attention of many researchers, some researchers analyzed the relationship 
between the structural and architectural works have considered severable, So that we can notice to the book of architecture and structure which is written by Angus J. MacDonald. He separate relationship with the architectural and structural in six topics.

Ornamentation of structure, Structure as ornament, Structure as architecture, Structure as form generator, Structure accepted, Structure ignored (Macdonald, 2001).

The interaction of structure and architecture has created a lot of changes at articulation of Architects and Construction Group. In the past, the prevailing ideas of the time by philosophers and religious scholars of their time were promoted. But now, based on the Innumerable human needs in various fields, we know different ideas but Convergent. Scholars of various disciplines have offered Different opinions and ideas to the community. But attention to the intellectual formations, depending on the convergence or non-convergence, is realized pervasive at their era. Modern Thought was founded based on the concept of the industrial age. Successive developments in thought and essences contemporary works change the style of architecture, reminiscent of modern thought. What was said, it is based speech that Buckminster Fuller presented to the world beyond time. Unwritten law but based on philosophies and theories in the entire world. Dialectical relationship thinkers such as Socrates, Aristotle, Plato to Hegel and modern thinkers like Derrida and ideas.... Ideas presented, now a days, scientist such as Fuller has presented dialectic relationship between elements of the building.

"All structures, properly understood, from the solar system to theatom, are Tensegrity structures. Universe is omnitensional integrity.” R. B. Fuller (Gómez, 2004).

According to Fuller, all structures are due of the system Tensegrity. Structure based on the dialectical relationship between the compressive members (repulsion) and simulators (attraction) is formed. Compression members have immersed in a sea of tension members. In Tensegrity structure, compressive members independently create prestressing and transfer forces to the foundation. Also tensile members are used to integrate and three-dimensional interact against incoming forces, force transmission and are used to complete the force flow process. Hence, Fuller considers of factors such as high efficiency, increased productivity and important than all, transparency in the awarding of the structural members, stated comprehensive definition of universal Tensegrity structures.

Advantage of Tensegrity can be mentioned self-stability, prestressing, expanded cargo area, higher efficiency of consumption materials and also the Simple connections. But the disadvantages of Tensegrity structure can be named difficult static and dynamic calculations, increasing the level of destruction point and in some cases, light weight structures.

But what is visible, minimalism is evident in the design of Tensegrity structures. But since the force flow direction has a significant role in the design of Tensegrity structures. Thus, according to the book written by Angus J. MacDonald Structure and Architecture, this structural system of the building can be considered Structure as form generator.

Structural requirements are allowed toinfluence strongly the forms of buildings even though the structure itself is not necessarilyexposed. In this type of relationship the configuration of elements which is mostsensible structurally is accepted and the architecture accommodated to it. The reasonwhy two cases are distinguished is that the closeness of the link between the architecturaland the structural agendas is subject to considerable variation. Sometimes it is very positive, with the form-generating possibilities of structure being used to contribute to an architectural style. Alternatively, even though the overall form of a building may have been determined largely to satisfy structural requirements, the architectural interest may lie else where (Macdonald, 2001).

At the first glance, it might seem that the architectural creativity of form defines the original path; complex Tensegrity structures after the computational challenges are reviewed to create the space needed for in modeling. These interactions lead to models will be fine.

\subsection{Funicular Structure and Their Interaction with Architecture}

With a little precision in construction of Tensegrity and funicular structures can be realized profound relationship between these two types of structures. Funicular structures are among the structures that are based on the form follow forces. Like the tree that have been bending against incoming loads then after eliminate loads goes back to its original state. These structures are kind of Structure as form generator. Books on Architectural structure, this structure along the arch, domes and shell structures, is the type of form-resistant structures.

The funicular concept can be best described and visualized with cables or chains (Figure 1), suspended from two points, that adjust their form for any load in tension. But funicular structures may also be compressed like arches. 
Although, funicular compressive structures may be subject to bending in addition to compression since their form is rigid and not adaptable. The funicular line for tension and compression are inversely identical; the form of a cable becomes the form of an arch upside-down. Thus funicular forms may be found on tensile elements (Engel \& Rapson).
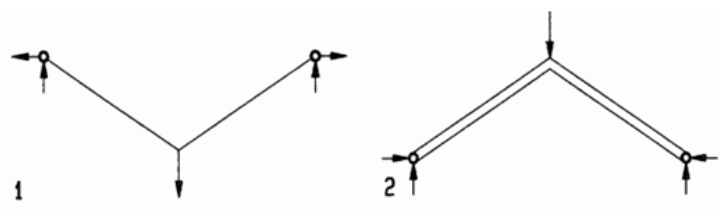

Figure 1. Funicular effect

Tensegrity systems constitute a very interesting example in between artistic expressions and structural engineering. They are characterized by a strong coupling between forms and forces, from simplex to complex cells (Motro, 2013).

Tensegrity structures are almost similar to funicular structures, Because of a network of tensile members are loaded by compressive members in the point where there arerebuild self-form again. But despite that, due to prestressing, after initial form finding, there is not deformation against further loads. But the form finding of funicular structures based on incoming loads. It is proof that can be asymmetrical but balanced final form design.

\subsection{Form-finding Method of Tensegrity Models}

\subsubsection{Types of Form-finding}

The coupling between forms and forces is one of the main topics of Structural Morphology. This coupling is very strong for systems in Tensegrity state, currently called "Tensegrity systems". Since some years the number of publications on Tensegrity systems is increasing (Motro, 2009).

There are many ways to design Tensegrity models so often Tensegrity models based on geometry, stability and statics of structure. Based on the paper presented by A. G. Tibertand and S. Pellegrino (Motro, 2009, pp. 1-19), Department of Engineering, University of Cambridge, can be classified into two methods, static and dynamic. Dynamic approach is concerned to the operational details of the built models, while the static method is used on the stability and sustainability of the model that based on the length of members and the balanced forces. Dynamic approach is concerned to the operational details of the built models, while the static method is used on the stability and sustainability of the model that based on the length of members and the balanced forces. But based on the initial model, Static and dynamic calculations effect on the prototype model and present a final form (Motro, 1992).

In addition, Seven form-finding methods for Tensegrity structures are reviewed and classified. The three kinematical methods include an analytical approach, a non-linear optimisation, and a pseudodynamic iteration. The four statical methods include an analytical method, the formulation of linear equations of equilibrium in terms of force densities, an energy minimisation, and a search for the equilibrium configurations of the struts of the structure connected by cables whose lengths are to be determined, using a reduced set of equilibrium equations (Tibert \& Pellegrino, 2011). In architecture, stable form is generated through an equilibration between many interdependent structural elements, each of which is independently in a state of disequilibrium. Complex architecture cannot be broken up into isolated pieces without losing qualities that are inherent to the structural whole (Ingber \& Jamieson, 2015).

However, the two methods mentioned above (Dynamic and static), Tensegrity model analysis has been evaluated, as previously explained, the next stage of the design and effectiveness of structural factors on the overall design of the model is considered. Among these, the most fundamental part of the design and construction of a prototype Tensegrity structures, engineers have not been considered. Initial models based on previous knowledge and are often regarded by architects. Because this is a fundamental part in creating a Tensegrity model, needy to architectural creativity and ideas in a creative mind and is free of algebraic computing. Structural engineers often encounter with problems that are based on mathematical calculations. There are various ways of the architect's ideas; among the methods that have been rarely considered by the architects, is the using reverse engineering. Reverse engineering methods are based on previous knowledge and preset strategies. Comprehensive definition 
of reverse engineering can be expressed as: Receive information from the existing Sample, Structural Analysis, Constituent elements and their relationships with each other, so that, Structural diagram can be drawn and the same sample can be built based on the obtained information.

But what is expected of an architect, beyond reverse engineering technique in order to achieve the desired aims of the Tensegrity structural model. According to Buckminster Fuller's statements and universality tensegrity structures.

\subsubsection{Form-finding Tensegrity by Fuller (Pflüger, 2008).}

Buckminster Fuller did not copy the principles from nature but he translated them into mathematical principles and this way made them comprehensible. When these principles are transferred, geodesic structures are of paramount importance. Edmondson quotes Fuller regarding this statement as follows: I did not copy nature's structural patterns. I began to explore structure and develop it in pure mathematical principle, out of which the patterns emerged in pure principle and developed themselves in pure principle. I then applied them to practical tasks. The reappearance of geodesic structures in scientists' findings at various levels of inquiry confirms the mathematical coordinating system employed by nature:

a) Tensegrity is a structural system composed of discontinuous compression elements connected by continuous tension cables.

b) There is a balance between tensional and compressive forces that maintains the stability of the structure.

c) Tensegrity structures act as "whole systems". External forces acting on them are transmitted to all elements of the structure in the same way. Vibration in one part of the structure causes vibration in all other parts.

d) The structures are efficient. They require only few materials and though the structures are very light, in fact they are very strong.

e) Tensegrity structures are self-stabilizing structures. Once the external force is removed, they will return to their original shape.

f) Pre-stress and triangulation are essential elements in a Tensegrity system.

g) The continuous tension elements do not have to be visible. Pneumatic and hydrostatic systems can be Tensegrity, e.g. a balloon.

h) Many structures in nature seem to be Tensegrity structures. They have the property of synergy. It is not possible to deduce the function of the whole by analysis of the parts.

\subsubsection{Reverse Engineering}

Reverse engineering has a long history as an accepted practice (Kremling, Fischer \& Gadkar, 2004)). Reverse engineering is the process of discovering the technological principles of a device, object, or system through analysis of its structure, function, and operation (Eldad, 2005). It often involves disassembling something (a mechanical device, electronic component, computer program, or biological, chemical, or organic matter) and analyzing its components and workings in detail, just to re-create it. Reverse engineering is done by maintenance or by creating a new device or program that does the same thing, without using original, or simply to duplicate it.

Reverse engineering has its origins in the analysis of hardware for commercial or military advantage (Chikofsky \& Cross, 1990). The purpose is to deduce design decisions from end of products with little or no additional knowledge about the procedures involved in the original production. The same techniques are subsequently being researched for application to legacy software systems, not for industrial or defense ends, but rather to replace incorrect, incomplete, or otherwise unavailable documentation (Nelson, 1996).

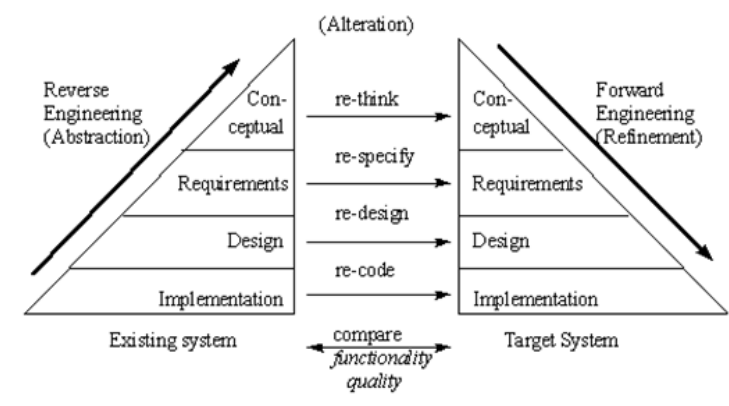

Figure 2. Reverse Engineering 
According to Figure 2, reverse engineering can be used for form-finding method of Tensegrity structures. Existed structures can be analyzed in term of force flow and distinguish compressive and tensile members from each other. In other words, we decompose it to reach it's design. Then, at the next step, understood it's design consequently it's requirements. Therefore, we can find concept of system or structure. These steps are the processes of reverse engineering. After that, we commence the process of Forward engineering. Concept has a veriety of references and it is variable, but requirements are extracted fundamentally Tensegrity principles. This is milestone of project and finally we start up implementation of Tensegrity structure. All of these processes called reverse engineering.

\section{Architectural and Structural Analysis of a Hammock}

\subsection{Natural Structures}

Nature developed over billions of years and, by the theory of Darwin, only the fittest organisms survived. This is probably the main reason to study nature in every part of science.

Loads are varying constantly. The wind speed and its direction changes and turbulence occur. There will be rain, snow or even hurricanes and even then, many organisms survive with minimum of damage. This is amazing if you think about the lightweight of these structures. Important for their resistance is their flexibility and compliance (Habraken, 2012).

Nature educates us about the advantages of flexibility. Allowing large deflections can reduce as well the impact of external forces as the development of internal forces. This way of using dynamic behavior is not common in the building industry.

Nature developed over billions of years and, by the theory of Darwin, only the fittest organisms survived. This is probably the main reason to study nature in every part of science.

\subsection{Background of Tensegrity Hammock}

In recent years, several models of Tensegrity Hammock have been made. The main point of these models was according to existed Tensegrity models like T-Prism or X model. The Tensegrity Hammock stand is freestanding, but it can tip over. Add stability and safety by staking each bottom eye bolt to the ground (Gurstelle, 2011).

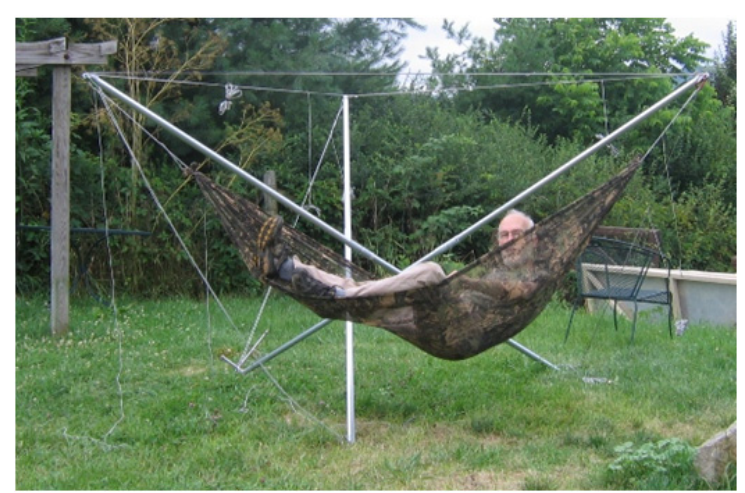

Figure 3. Tensegrity Hammock (Gurstelle, 2011)

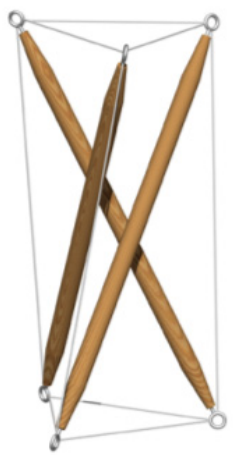

Figure 4. Tensegrity prism 
The T-prism is illustrated in Figure 4. It is the simplest and therefore one of the most instructive members of the tensegrity family. Some art historians believe it was first exhibited by the Latvian artist Karl Ioganson in Moscow in 1920-1921 though this claim is controversial (Burkhardt, 2004; Motro, 2003).

\subsection{Hammock}

Based on reasons of choosing Hammock which are mentioned in the introduction section, Hammock has a miracle structure among others. As you know, it is very simple and elementary. Despite it is prototype of coastal structure, but it has several features that are very prominent. Interaction between structure and architecture, ability of showing it's structure as compressive and tensile members. These features make us able to use simple analysis to describe it modest way.

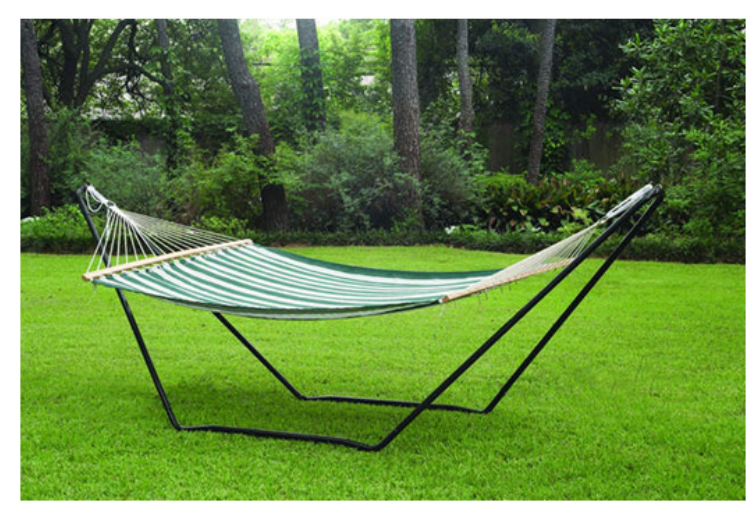

Figure 5. Hammock

According to Figure 5 it is easy to understand function of members. It has 6 studs and membrane with tensile function. After defining member function, it is the time of decomposition and implement of Tensegrity principles on it.

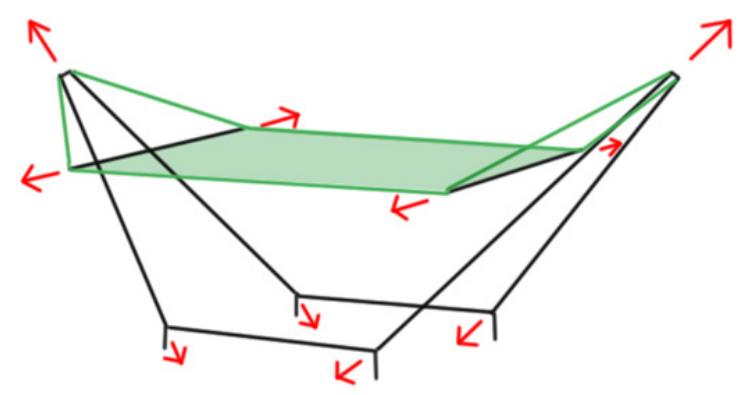

Figure 6. Analysis of Hammock

\section{Compessive members \\ Tensile members}

It is obvious that in this structure stability is not an aim. But, in the Tensegrity structure, we need stability of structure because of architectural aims. Therefore, we must add some tensile members and also change the position of compressive members. At first glimpse, it is possible to design prototype of Tensegrity Hammock. 


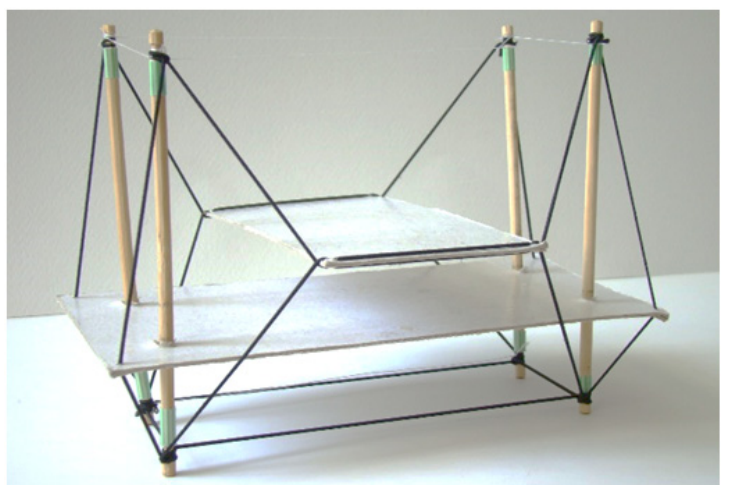

Figure 7. Prototype of Tensegrity Hammock

After following up structural node points, indicating of members will be possible. Compressive members float in tensile members.

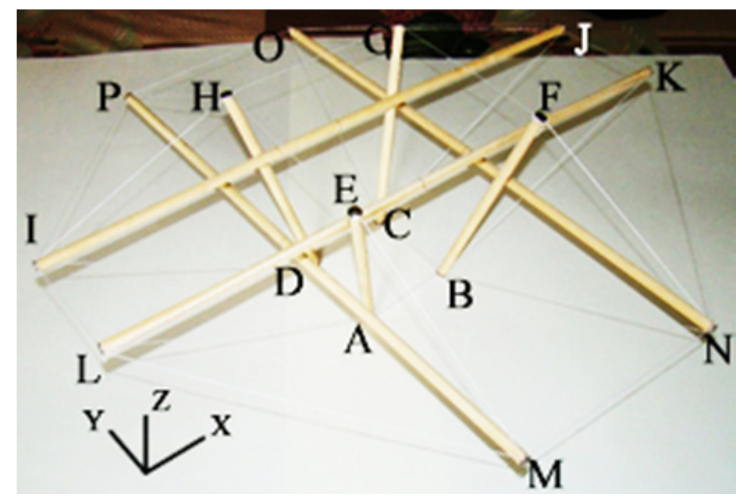

Figure 8. Nodes

The length of studs are:

Table 1. Length of Studs

\begin{tabular}{ll}
\hline Stud & Length $(\mathrm{cm})$ \\
\hline $\mathrm{AE}$ & 3.08 \\
$\mathrm{BF}$ & 3.08 \\
$\mathrm{DH}$ & 3.08 \\
$\mathrm{CG}$ & 3.08 \\
$\mathrm{IJ}$ & 6 \\
LK & 6 \\
$\mathrm{MP}$ & 6 \\
$\mathrm{NO}$ & 6 \\
\hline
\end{tabular}

Deviation from vertical line is 9 degree. In other words, Their angle is 81 degree.

These studs have been made by wood and tensile members are string. The only thing has been considered was Architectural aspects and stability of model by loading which are involved in the field of architecture. Thinking about Non-interference between architecture and structure and also consider interaction between them are the ideal of design. 
Table 2. Coordinate

\begin{tabular}{llll}
\hline \multirow{2}{*}{ Point } & \multicolumn{3}{l}{ Coordinate } \\
\cline { 2 - 4 } & $\mathrm{X}$ & $\mathrm{Y}$ & $\mathrm{Z}$ \\
\hline $\mathrm{A}$ & 0 & 0 & 0 \\
$\mathrm{~B}$ & 1 & 0 & 0 \\
$\mathrm{C}$ & 1 & 1 & 0 \\
$\mathrm{D}$ & 0 & 1 & 0 \\
$\mathrm{E}$ & -0.05 & -0.5 & 3 \\
$\mathrm{~F}$ & 1.5 & -0.05 & 3 \\
$\mathrm{G}$ & 1.5 & 1.5 & 3 \\
$\mathrm{H}$ & -0.05 & 1.5 & 3 \\
$\mathrm{I}$ & -2.5 & 1.25 & 2 \\
$\mathrm{~J}$ & 3.5 & 1.25 & 2 \\
$\mathrm{~K}$ & 3.5 & -0.25 & 2 \\
$\mathrm{~L}$ & -2.5 & -0.25 & 2 \\
$\mathrm{M}$ & -0.25 & -2.5 & 1 \\
$\mathrm{~N}$ & 1.25 & -2.5 & 1 \\
$\mathrm{O}$ & 1.25 & 3.5 & 1 \\
$\mathrm{P}$ & -0.25 & 3.5 & 1 \\
\hline
\end{tabular}

The ultimate model is presented in Figure 7. For embedding architectural space within Tensegrity structure, The priority is to get back to the prototype presented in Figure 5. Two levels are accessible for acceptance of duty of place for users.

These place are similar to membrane part of Hammock which was made of fabric. Therefore, for being stable, it is fundamental to make this part prestress according to tensile state of prototype. The best part can be here. Because, all knowledge can be useful as a complementary. Cable net or other type of tensile structures will be notable.

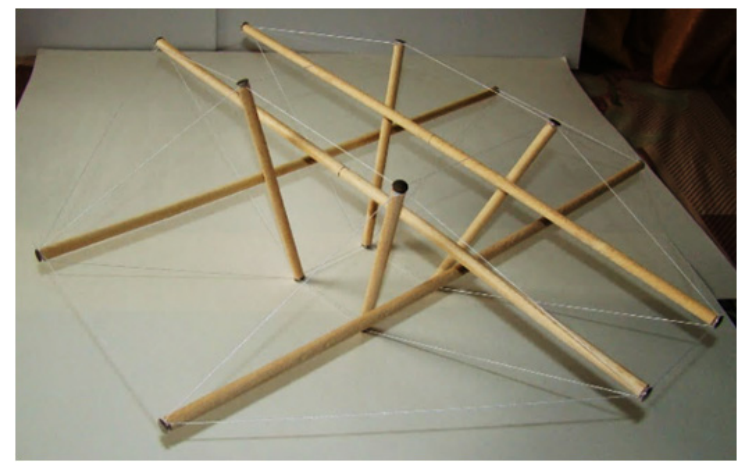

Figure 9. Tensegrity Hammock

Therefore, by completing this part of Tensegrity Hammock, it is ready for defining architectural space on it.

\section{Conclusion and Outlook}

According to all processes of Tensegrity Hammock design, we can imply that it is possible to extract Tensegrity models from existed structures. This fact has two aspects. First, we can design Tensegrity structure without any dependency to symmetric models. Therefore, it makes us hopeful that development of future Tensegrity will breakthrough to new kind of systems. The other aspect is interaction of architectural space and structure. This feature is highlighted because it can change procedure of using Tensegrity structure which are used for covering vast area and also using for case study like mast, sculpture, and so on. This result let designer to involve Aesthetic issues of Tensegrity Simultaneously with other parameters. This process is useful for conceptual design and it makes design possible to adapt with environment, formalism and so on. Totally, it is new point of view toward world by using Fuller's viewpoint that Universe is Omni tensional integrity. According to this approach, this dream come truth. 


\section{Reference}

Burkhardt, R. W. (2004). A Practical Guide to Tensegrity Design. Cambridge, USA. Retrieved from http://www.channell.com/users/bobwb/tenseg/book/cover.html, December 2003-August 2004

Chikofsky, E. J., \& Cross, J. H. (1990). Reverse Engineering and Design Recovery: A Taxonomy. IEEE Software 7 (1), 13-17. http://dx.doi.org/10.1109/52.43044

Eldad, E. (2005). Reversing secrets of reverse engineering. ISBN 978-84-8102-575-0.

Engel, H., \& Rapson, R. (2007). Structure Systems. Publisher: Hatje Cantz Verlag, ISBN 13- 9783775718769.

Gómez, J. V. (2004). Tensegrity Structures and their Application to Architecture, MSc in Architecture in Architecture science. School of Architecture Queen's University Belfast, ISBN 978-84-8102-575-0.

Gurstelle, W. (2011). How to Build a Three-Person Hammock. Retrieved from http://www.popularmechanics.com/home/lawn-garden/how-to/a6822/how-to-build-a-three-person-Hammoc $\mathrm{k} /$

Habraken, A. (2012). Flexible Structural Façade. Assistant Professor TU/e Eindhoven University of Technology, Faculty of Building and Architecture Eindhoven, the Netherlands. Retrieved from http://www.tue.nl

Ingber, D. E., \& Jamieson, J. D. (2015, February 11). Cells as tensegrity structures, architectural regulation of histodifferentiation by physical forces transducer over basement membrane (pp. 13-32). Orlando: Academic Press.

Kremling, A., Fischer, S., \& Gadkar, K. (2004). A Benchmark for Methods in Reverse Engineering and Model. Discrimination: Problem Formulation and Solutions.

Macdonald, A. J. (2001). Structure and Architecture (2nd Ed.). Department of Architecture, University of Edinburgh, ISBN 07506 47930, Chapter7.

Motro, R. (1992). Tensegrity Systems: The State of the Art. International Journal of Space Structures, 7(2), 75-84.

Motro, R. (2003). Tensegrity structural system for the future (pp. 8-10). London and Sterling, VA. ISBN 19039 96376.

Motro, R. (2009). Structural morphology of Tensegrity structure. Asian Journal of Civil Engineering (Building and Housing), 10(1), 1-19.

Motro, R. (2013). Tensegrity: From Art to Structural Engineering. IASS-APCS Symposium. https://hal.archives-ouvertes.fr/hal-00857410

Nelson, M. L. (1996). A Survey of Reverse Engineering and Program Comprehension. ODU CS 551-Software Engineering Survey. ArXiv: cs /0503068v1

Pflüger, C. (2008, October). The Meaning of Tensegrity Principles for Osteopathic Medicine (pp. 20-21). Master thesis for the degree Master of Science in Osteopathy submitted at the Donau University Krems and the Vienna School of Osteopathy.

Pugh, A. (1976). An introduction to Tensegrity. University of California, Berkeley and Los Angeles, printed in the United States of America, ISBN 13-9780520030558.

Tibert, A. G. (2002). Deployable Tensegrity Structures for Space Applications. Doctoral Thesis in mechanics science, Royal Institute of Technology Department of Mechanics Royal Institute.

Tibert, A. G., \& Pellegrino, S. (2003, April 7-10). Deployable Tensegrity Masts, $44^{\text {th }}$ AIAA/ASME/ASCE/AHS/ASC Structures, Structural Dynamics and Materials Conference and Exhibit, Norfolk, VA.

Tibert, A. G., \& Pellegrino, S. (2011). Review of Form-Finding Methods for Tensegrity Structures. International Journal of Space Structures September, 26(3), 241-255.

\section{Copyrights}

Copyright for this article is retained by the author(s), with first publication rights granted to the journal.

This is an open-access article distributed under the terms and conditions of the Creative Commons Attribution license (http://creativecommons.org/licenses/by/3.0/). 